\title{
Psicologia e Democracia em um Cenário de Cidade como Campo em Disputa
}

\author{
Elisa Martins \\ Fhillipe Pereira \\ Universidade Federal do Rio de Janeiro, RJ, Brasil. \\ Universidade Federal do Rio de Janeiro, RJ, Brasil. \\ Gabriela Salem \\ Lucas Gabriel de Matos Santos \\ Universidade Federal do Rio de Janeiro, RJ, Brasil. \\ Universidade Federal do Rio de Janeiro, RJ, Brasil. \\ Roberta Brasilino Barbosa \\ Universidade Federal do Rio de Janeiro, RJ, Brasil.
}

\begin{abstract}
Resumo: No Rio de Janeiro, o planejamento urbano e o direito à cidade vêm sofrendo contundentes interferências do modelo neoliberal, colocando em conflito os interesses de quem habita o território e os das grandes corporações do capital financeiro. Tais interferências agravam problemas já conhecidos dos cariocas, como negação de direitos básicos, criminalização da pobreza e aumento do custo de vida. No presente texto, trabalhou-se com a ideia de cidade não como palco de uma disputa sócio-histórica de classes ou como objeto dessa disputa, mas como o emergir da própria disputa. Interessa-nos analisar e discutir os efeitos desse confronto, além de elaborar formas de resistência e de superação das desigualdades que marcam a experiência humana na realidade social brasileira. Nesse cenário, faz-se necessária a construção de outro modo de fazer Psicologia, comprometido em reunir elementos de ação capazes de intervir na realidade que vem sendo imposta a partir da perspectiva de cidade-negócio. Uma Psicologia que tenha a luta e participação política como metas para uma experiência democrática de sociedade, consolidando dessa forma o compromisso social como norteador da profissão.
\end{abstract}

Palavras-chave: Direito à Cidade, Psicologia, Participação Social.

\section{Psychology and Democracy in a Scenario of the City as a Disputed Field}

\begin{abstract}
In Rio de Janeiro, urban planning and the right to the city have been suffering neoliberal model's strong interference, putting into conflict the interests of those who dwell the territory and the large corporations of the financial capital. That interference exacerbates problems already known by cariocas, such as the denial of basic rights, the criminalization of poverty and an increase in the cost of living. In the present text, we worked with the idea of city not as the stage of a historical social class dispute or as the object of this dispute, but as the emergence of the dispute itself. We are interested in analyzing and discussing the effects of this dispute, as well as in elaborating ways of resistance and overcoming the inequalities that mark human experience in the Brazilian social reality. In this scenario, it is necessary to construct another way of doing Psychology, committed to gathering elements of action capable of intervening in the reality that has been imposed from the perspective of the entrepreneurial city. A Psychology that has struggle and political participation as goals for a democratic experience of society, thus consolidating social commitment as a guide to the profession.
\end{abstract}

Keywords: Right to City, Psychology, Social Participation. 


\title{
Psicología y Democracia en un Escenario de Ciudad como Campo en Disputa
}

\begin{abstract}
Resumen: En Río de Janeiro, la planificación urbana y el derecho a la ciudad vienen sufriendo contundentes interferencias del modelo neoliberal, poniendo en conflicto los intereses de quienes habitan el territorio y los de grandes corporaciones del capital financiero. Tales interferencias agravan problemas ya conocidos por los cariocas, como negación de derechos básicos, criminalización de la pobreza y aumento del costo de vida. En el presente texto, vamos a trabajar con la idea de ciudad no como escenario de una disputa socio-histórica de clases o como objeto de esa disputa, sino como el emerger de la propia disputa. Nos interesa analizar y discutir los efectos de esa confrontación, además de elaborar formas de resistencia y de superación de las desigualdades que marcan la experiencia humana en la realidad social brasileña. En ese escenario se hace necesaria la construcción de otro modo de hacer Psicología, comprometido con reunir elementos de acción capaces de intervenir en la realidad que viene siendo impuesta desde la perspectiva de ciudad-negocio. Una Psicología que tenga la lucha y participación política como metas para una experiencia democrática de sociedad, consolidando de esa forma el compromiso social como orientador de la profesión.
\end{abstract}

Palabras clabe: Derecho a la Ciudad, Psicología, Participación Social.

\section{Introdução}

Os trabalhadores subalternizados (Silva, \& Barbosa, 2005) da cidade do Rio de Janeiro sofreram diversas vezes com os despejos forçados ao longo da história. Apesar de não ser novidade, recentemente, em razão de megaeventos esportivos e das transformações urbanísticas que impuseram à cidade, esse processo se intensificou, ao negar o direito à moradia de milhares de famílias cariocas. De acordo com dados do Dossiê do Comitê Popular da Copa e Olimpíadas do Rio de Janeiro (2015), até novembro de 2015, 22.059 famílias haviam sido removidas na cidade do Rio de Janeiro. Moradores de diversas comunidades da cidade foram e continuam sendo forçados a sair de suas casas, seja pela intervenção direta do Estado, para o desenvolvimento dos megaeventos ou por estarem em "áreas de risco", seja devido às forças da especulação imobiliária e da gentrificação.

Entendemos que moradia está para muito além de quatro paredes. Ao negar esse direito, se está negando também os direitos à saúde, à educação, ao trabalho e ao lazer. As remoções obrigam os moradores a mudarem-se para áreas periféricas, onde a terra vale menos. Novas favelas são formadas e conjuntos residenciais de reassentamento são construídos. Esse processo se dá de forma antidemocrática, sem participação da população, nem ao menos da comunidade que sofrerá diretamente essas transformações. O modelo neoliberal, ao transformar moradia em negó- cio, nega políticas que entendam a dimensão social da moradia e a compreensão dela mesma como um direito humano. Na lógica do mercado imobiliário, o lucro importa mais que a vida das pessoas e o valor da terra é medido em dólares ou reais, em vez de memória e história.

Como já propôs Santos (1999), o espaço é um importante elemento para a constituição do sujeito e para a compreensão da dinâmica social, pois é no espaço da cidade que homens e mulheres imprimem sua marca, desenvolvem relações e sobrevivem. A história não se escreve fora do espaço. Neste sentido, entendemos a grande importância de fazer uma reflexão sobre a relação espaço-subjetividade e pensar sobre os impactos subjetivos da segregação espacial. É impossível dissociar a cidade do sujeito que nela habita, da mesma forma que, para uma apreensão da cidade, é preciso pensar em seus moradores. A Psicologia que tem como norte o compromisso social precisa considerar o espaço urbano como elemento imprescindível para a compreensão da dimensão subjetiva, pois, ao passo que o sujeito transforma a cidade, ele também é transformado por ela.

Dessa maneira, é papel da Psicologia contribuir com práticas que afirmam uma visão de cidade que não privilegie o espaço urbano para especulação e obtenção de lucro, mas que considere, primeiramente, o bem-estar daqueles que a habitam. É preciso elaborar outro modo de fazer Psicologia, que tenha na luta e participa- 
ção política metas para uma experiência democrática de sociedade, o que necessariamente passa pela experiência de cidade.

Nesse intuito desenvolvemos um projeto de trânsito pela cidade, mencionado na segunda parte do texto, com jovens moradoras e moradores da região da Comunidade Indiana Tijuca e do Complexo do Borel. Uma tentativa de problematizar questões que os afetam diretamente, no que se refere ao direito à cidade. Apostamos na própria mobilização social do grupo como estratégia metodológica de trabalho, entendendo que a articulação do coletivo pode ser um instrumento promotor de autonomia, capaz de estimular uma participação política, social e democrática, e contribuindo para a resistência às transformações que aquele espaço urbano tem sofrido e que afetam as interações sociais das pessoas que ali habitam.

\section{Cidade como campo em disputa}

Pensemos inicialmente na cidade enquanto uma sobreposição de lugares que acontecem, de hábitos, de movimentos, de existências, de sistemas, ou, o que sugere Santos (2006), um eixo de sucessões de acontecimentos e um eixo de coexistências em um lugar, o que faz com este lugar seja instável e não homogêneo. As diversas linhas sobrepostas que existem na cidade nos ajudam a enxergá-la como um lugar de diversos eventos, como o espaço do acontecer, e que, a partir das rupturas e linhas que se chocam, dão lugar a outros eventos (Santos, 2006). Cada acontecer é, ao mesmo tempo, causa e efeito de outros eventos e essa influência, com a globalização, alcança uma universalidade cada vez maior. O que acontece a nível global pode fazer surgir ou alterar eventos locais, e um evento local pode criar desvios a níveis globais. Temos então o local enquanto o lugar da interação da vizinhança, da intimidade, do que é marcado na medida em que marca o território, do morador, e que responde, do seu modo, à racionalidade global; e o global, que busca impor uma única racionalidade, e que se apresenta como normas, métodos e padrões. Esses entendimentos de Santos (2006) se aproximam do que Lefebvre (2001, p. 52) traz como a ordem distante (global) e a ordem próxima (local):

A ordem distante, se institui em um nível superior, isto é, neste nível dotado de poderes. Ela se impõe, abstrata, formal, supra-sensível, e trans- cendente na aparência, não é concebida fora das ideologias (religiosas, políticas). Comporta princípios morais e jurídicos. Esta ordem distante se projeta na realidade prático-sensível. Torna-se visível ao se inscrever nela. Na ordem próxima, e através dessa ordem, ela persuade, o que completa seu poder coator. Ela se torna evidente através e na imediatez.

Santos (2006) traz estas duas razões, global e local, de uma maneira dialética, que não só se associam, mas se contradizem, se complementam, mas também se confrontam. Interessa-nos analisar o que é produzido e produz um desses confrontos, dessas contradições, trazendo o que chamamos de "disputa pela cidade”. Em tempos de globalização e neoliberalismo, no qual a intervenção estatal em regimes de bem-estar social se apequena frente às exigências de um mercado especulativo em constante movimento, a discussão sobre cidade enquanto um campo em disputa é fundamental. É preciso entender os efeitos e desdobramentos do sentido contemporâneo dado ao espaço urbano, não mais como um lugar de condições necessárias para acumulação do capital, mas que reproduz diretamente o capital enquanto se é produzido como espaço (Carlos, Volochko, \& Alvarez, 2015). Portanto, não traremos a cidade como palco de uma disputa social e histórica entre classes, e nem como objeto dessa disputa, por entendermos que a cidade deixa de ser apenas o local onde ocorre acumulação de capital e passa a ser o próprio objeto/produto dessa transação. A cidade é produzida a partir da lógica do mercado, sendo produto e ao mesmo tempo espaço de produção. A cidade em si emerge da disputa.

Para ilustrar a "disputa pela cidade", colocaremos em análise um dos critérios apresentados pela Secretaria Nacional de Direitos Humanos para garantia de moradia adequada: a segurança de posse (Brasil, 2013). O tema foi recentemente discutido na Organização das Nações Unidas (ONU) em meio à crise mundial de insegurança de posse, segundo a relatora especial da ONU sobre direito à moradia adequada, Raquel Rolnik (ONUBR, 2013). Avila e Ferreira (2016) situam o tema na falta de precisão do domínio do solo, no entanto Rolnik (2015) traz como a impossibilidade de se permanecer no local onde mora. Segundo o caderno Direito à Moradia Adequada emitido pela Secretaria Nacional de Direitos Humanos, "a moradia não é adequada se os seus ocupantes não têm um 
grau de segurança de posse que garanta a proteção legal contra despejos forçados, perseguição e outras ameaças" (Brasil, 2013, p. 14). São inúmeros os motivos por trás da insegurança de posse, sejam conflitos armados, desastres naturais, projetos de infraestrutura ou de exploração econômica.

Uma inundação, o avanço de uma hidroelétrica ou um grande projeto de instalações esportivas sobre um território habitado, tem impactos mais agudos quando ocorre sobre territórios cuja situação de posse pode ser contestada a qualquer momento por autoridades ou agentes privados (Rolnik, 2015, p. 150).

Esses impactos podem ser vistos na fragilização ao direito constitucional de moradia' ${ }^{1}$, nos riscos de despejos forçados e a invasões de terceiros, no desinteresse na melhoria das condições de habitação e em problemas de ordem social e econômica (Avila, \& Ferreira, 2016).

As estruturas de poder que servem a uma racionalidade (global) de espaço incidem sobre os moradores da cidade e podem culminar, por fim, em mecanismos de inclusão/exclusão (Rolnik, 2015). Ao sugerir este processo, estamos tomando a especulação imobiliária, o planejamento urbano e o uso da terra como estratégias dessas estruturas de poder para possibilitar ou não o acesso a certos locais por determinado grupo de pessoas. Não estamos descrevendo ainda os processos de remoções forçadas, mas um processo mais sutil, que nega o direito à cidade e à moradia quando, ao invés de suprir necessidades básicas sociais, econômicas e de saneamento, investe em novas estruturas, em um planejamento urbano que não contempla os interesses locais, o que faz com que o valor imobiliário aumente, assim como o custo de vida. Famílias que, sem condições de se manterem com a nova configuração do local, precisam procurar lugares mais acessíveis economicamente para morar, o que pode significar também lugares sem infraestrutura e rede de serviços adequados, distante dos locais de trabalho e com transporte precarizado, com pouca segurança e sem nenhuma ligação afetiva com o espaço. Esse é o processo de gentrificação do espaço.

A cidade, habitada e habitável, com características históricas, sociais e culturais próprias do espaço, é sumariamente transformada em seu espaço urbano pelas exigências de um ideal de cidade e com um "bom visual", que sirva de marketing, ou um bom lugar para receber investimentos do capital estrangeiro. Leis são alteradas e criadas, agências e conselhos com poderes de decisão (sem representatividade), políticas higienistas e de remoção, violadoras de direitos (Rolnik, 2015).

A autora pontua a emergência do que é chamado de "empreendedorismo municipal": o governo deixa a visão administrativista e passa a empreender a cidade, a envolvê-la na especulação financeira, nas estratégias globais de localização de multinacionais e transforma as políticas urbanas em promoção econômica e megaprojetos globais. Um reflexo disso é o crescimento de parcerias públicos-privadas (PPP), associação vasta entre dois setores da economia distintos das concessões e das privatizações. As PPPs surgem sob o pretexto do avanço de competências exigidas pelo mercado e não alcançadas pelos aparelhos estatais. Elas são em sua maioria relacionadas a megaprojetos de desenvolvimento urbano conduzidas e financiadas pelo Estado que assume também os riscos de possíveis déficits. Como se deu na zona portuária do Rio de Janeiro, por exemplo, que virou um complexo imobiliário-financeiro, em execução por meio de uma PPP encarregada de gerir os serviços por 15 anos e implementar as obras, as quais foram realizadas sem diálogo com os moradores do local e dos arredores e que geraram remoções de diversas famílias (Rolnik, 2015).

Em "SMH 2016: Remoções no Rio de Janeiro Olímpico", Faulhaber e Azevedo (2015) evidenciam os processos de exclusão na cidade do Rio de Janeiro compreendidos em um projeto de cidade para recepção dos megaeventos. Segundo esses autores, inicialmente a população carioca apoiou uma imagem valorizada de cidade, capaz de atrair público e capital estrangeiro, pois seriam beneficiários dos avanços da cidade. No entanto, deparam-se com o alto custo para a construção de equipamentos esportivos subutilizados, o aumento expressivo no custo de vida que atinge não somente as faixas mais pobres, mas também a classe média, e com processos de remoções e desapropriações em favelas já consolidadas. Processos incentivados pelos interesses do Estado e das grandes construtoras em locais ocupados e que são alvos da especulação imobiliária, como os arredores

${ }^{1}$ Art. $6^{\circ}$ São direitos sociais a educação, a saúde, a alimentação, o trabalho, a moradia, o transporte, o lazer, a segurança, a previdência social, a proteção à maternidade e à infância, a assistência aos desamparados, na forma desta Constituição (BRASIL, 1988). 
do estádio Maracanã, com as remoções de favelas como a Metrô Mangueira (Williamson, 2012), como o Parque Olímpico na Barra da Tijuca, com o caso da Vila Autódromo (Talbot, 2016), e como da Região Portuária (Robertson, 2016), no centro do Rio de Janeiro.

Foram mais de 20 mil casas removidas em cinco anos de governo. E ao que parece, o processo de reestruturação em curso deve reforçar o padrão centro-periferia com acentuação de uma descentralização que se expressa no processo de segregação, sem garantia de manutenção das estruturas ocupacionais para os moradores removidos, como resultado de uma série de políticas, programas e intervenções (Faulhaber, \& Azevedo, 2015. p. 77).

O dossiê sobre megaeventos e violações de direitos humanos, lançado pelo Comitê Popular da Copa e das Olimpíadas no Rio de Janeiro em 2015, sintetiza a atual política como uma política de exclusão, a partir da subordinação da cidade ao capital e não às pessoas. De acordo com o documento, as violações de direitos se intensificaram com os megaeventos, como o direito à moradia, à mobilidade, ao meio ambiente e o direito das cidadãs e cidadãos de terem acesso à informação e participar da tomada de decisões. O relatório diz dos processos de elitização e mercantilização da cidade e dos novos padrões de relação entre o Estado e os agentes econômicos e sociais, marcados pela negação das esferas públicas democráticas de processos decisórios, falta de transparência e intervenções autoritárias. De forma semelhante, a ONG Internacional Justiça Global produziu um relatório acusando o desrespeito aos direitos das moradoras e moradores das favelas e periferias da cidade do Rio de Janeiro, durante a preparação para os Jogos Olímpicos, na tentativa de tornar público o lado que não é visto na televisão, como a violência policial, o extermínio da população negra e pobre, o aprofundamento da segregação socioespacial e o controle e privatização do espaço público.
O pluralismo jurídico pode nos ajudar a entender como se dá essa negação de direitos, como o direito à moradia, por exemplo. Ao se tratar de territórios, lugares, espaços, Rolnik (2015) aponta o pluralismo jurídico como "o encontro, coexistência e, muitas vezes, conflitos entre diferentes ordens judiciais que operam sobre o mesmo território" (p. 176). Interessa-nos discutir como esse pluralismo jurídico reflete e reproduz desigualdades sociais. "Vivemos em um mundo no qual os direitos de propriedade privada e a taxa de lucro se sobrepõe a todas as outras noções de direitos em que se possa pensar" (Harvey, 2014, p. 27). Não é diferente tratando-se do direito à cidade. Harvey (2014) traz, enquanto direito à cidade, algo muito maior do que um direito de acesso individual ou grupal aos recursos que a cidade incorpora, mas é principalmente um direito de mudar e reinventar a cidade de acordo com os nossos interesses. Dessa forma, quando o lucro e a especulação colocam-se como prioridade e o poder público não possibilita uma democracia participativa, a reinvenção e mudança são extremamente desafiadoras.

Segundo Rolnik (2015), o sistema jurídico-burocrático não é capaz de lidar com a transitoriedade legal/ilegal permanente ${ }^{2}$ marcada pela constituição do espaço contemporâneo, pois quando se trata de pluralismo jurídico, não consideramos apenas uma plural legislação territorial ou ordens urbanísticas distintas que coexistem, mas também "das relações de ordem, autoridade e poder presentes nos bairros populares autoproduzidos" (Rolnik, 2015, p. 177). Com isso, as soluções extrajudiciais aparecem como resoluções possíveis, seja pela mediação, arbitragem ou pela discricionariedade ${ }^{3}$. No entanto, essas resoluções geralmente estão situadas no âmbito político, tendo o Estado como mediador. Rolnik (2015) chama a atenção para a necessidade de afastar a ideia de que a consolidação de bairros populares ou favelas são lugares em que o Estado não está presente, assim como Magalhães (2013) que reafirma a necessidade em não entender a favela como espaço composto por um vácuo jurídico, uma terra sem lei. Marginalizada em sua estrutura, sis-

\footnotetext{
${ }^{2}$ No contexto deste artigo, ao falarmos transitoriedade permanente estamos nos referindo transição legal/não-legal que envolve um território e sua constituição. Um exemplo de como isso está presente: quando se ocupa uma terra vazia, se possuir proprietário, a ocupação é ilegal, no entanto se não possuir um proprietário formal, ou ser objeto de disputa, a ocupação pode não ser contestada de maneira imediata e, por fim, consolidada (Rolnik, 2015).

${ }^{3}$ Qualidade do poder conferido à administração pública; “A essência do poder discricionário está na liberdade de proceder, por meio de apreciações subjetivas, à adoção de uma ou mais soluções possíveis, tomando decisões com valor igual à que teria podido dar o legislador" (Grotti, 2000, p. 71). Este poder assegura a supremacia da administração pública sobre a particular.
} 
tematicamente considerada ilegal, tendo em vista as constantes tentativas de regulação dos espaços ocupados e consequentemente afastada da ideia de "cidade formal", a favela acaba por ser desconsiderada quando se trata de investimentos públicos ou em possíveis planejamentos de atendimento às populações que moram nesses espaços. A não atuação do Estado nos espaços das favelas não pode ser entendida como uma ausência, mas sim como uma política específica, uma determinada forma de agir, com um fim outro que não é a emancipação e a garantia de direitos. "As idas e vindas de processos de formação, consolidação e remoção desses assentamentos têm sido fortemente constituídas e permanentemente mediadas pelo Estado" (Rolnik, 2015, p. 180).

O mesmo Estado possui interesses eleitoreiros e econômicos. Possibilita por meios legais a existência/permanência de assentamentos em troca de uma moeda político-eleitoral (Rolnik, 2015), e também atua segundo os interesses do mercado, influenciado pelas grandes empresas que figuram nos quadros de maiores financiadores de campanhas eleitorais. Neste sentido, o Estado neoliberal diminui suas atuações apenas em políticas sociais, pois, enquanto políticas econômicas, ele somente se adequou às exigências do mercado (Maricato, 2009). Rolnik (2015, p. 181) completa: "este mecanismo tem sido fundamental para manter a desigualdade e o controle da cidade pelas elites, ao mesmo tempo que reproduz mandatos políticos, constituindo vastas bases eleitorais para os partidos".

\section{Compromisso social da Psicologia frente ao cenário}

No ano de 2013, a equipe do Escritório Modelo de Arquitetura e Urbanismo da Universidade Federal do Rio de Janeiro (EMAU-UFRJ), Abricó, deu início à execução de um projeto de extensão numa favela carioca chamada Indiana (que possui 887 habitantes, segundo censo do Instituto Brasileiro de Geografia e Estatística - IBGE de 2010, fica localizada no bairro da Tijuca e é integrante do Complexo do Borel), somando esforços a outras iniciativas que visavam barrar o processo de remoção que ameaçava as famílias que lá residiam ${ }^{4}$. A partir de 2016, os arquitetos urbanistas em formação entenderam que seria importante nessa empreitada a construção de um plano participativo de urbanização, para o qual convidaram a equipe de Psicologia do Núcleo Interdisciplinar de Ações para Cidadania da mesma universidade (NIAC-UFRJ) ${ }^{5}$ a contribuir. Um plano de urbanização participativo, que pudesse servir de instrumento técnico de luta política para a comunidade, enquanto uma ação de enfrentamento aos recorrentes processos de remoções e outras violações que vem acompanhadas.

Das ações interdisciplinares entre as áreas de Psicologia e Arquitetura e Urbanismo em parceria com instituições e moradores da supracitada comunidade surgiu um projeto de intervenção, cuja atividade principal passamos agora a descrever. Trata-se da realização de experiências recreativas de trânsito pela cidade do Rio de Janeiro, com jovens da comunidade, seguidas de rodas de conversa sobre temas relacionados ao direito à cidade, tendo como impulsionador a construção de subsídios para o plano participativo de urbanização.

As políticas públicas de planejamento urbano têm promovido intensas transformações no espaço da cidade do Rio de Janeiro, considerando majoritariamente os interesses econômicos e políticos que favorecem grupos mais abastados da sociedade, tal qual discutiu-se em seção anterior. Tais mudanças atingem, na maioria das vezes de maneira violadora, comunidades de determinadas áreas da cidade. As mesmas ocasionam remoções e desapropriações que resultam em transferências das famílias para áreas distantes de onde são originárias, ferindo o direito básico à moradia (Faulhaber, \& Azevedo, 2015). Para

\footnotetext{
${ }^{4}$ Em 2010, a Prefeitura do Rio anunciou a remoção de 119 comunidades, incluindo Indiana até o final de 2012 (Bastos, \& Schmidt, 2011). A partir de então, sobretudo em janeiro de 2012, a comunidade foi alvo de uma campanha de expulsão. Sob o argumento de que algumas famílias moravam em áreas de risco, o então secretário de habitação, Jorge Bittar (PT-RJ), informou aos moradores que aqueles que residiam às margens do rio Maracanã seriam removidos para Triagem, onde estava sendo construído o Bairro Carioca, com recursos do programa Minha Casa, Minha Vida, do governo federal. Em resposta, os moradores se organizaram em uma comissão e procuraram a Defensoria Pública do Estado do Rio de Janeiro para questionar a legalidade das ações da Prefeitura e montar um projeto judicial. Enquanto isso, entre março e outubro de 2012, 110 famílias foram removidas. Em dezembro desse mesmo ano, ocorreu uma audiência pública na qual a prefeitura não conseguiu justificar as remoções e uma ordem judicial foi emitida considerando as ações da prefeitura violadoras e proibindo mais demolições (Clarke, 2014).

${ }^{5}$ O NIAC, programa de extensão da UFRJ, foi criado em 2006 e integra projetos de pesquisa e extensão orientados para promoção do acesso à justiça e à cidadania. Atuam nesse programa equipes formadas por integrantes dos cursos de Psicologia, Serviço Social e Direito da UFRJ.
} 
além disso, é importante ressaltar que essas políticas frequentemente dificultam a mobilidade da população, bem como o acesso a equipamentos de saúde, cultura, de esporte e de lazer. Elas se preocupam de maneira diferenciada com os territórios urbanos, não considerando em seus planejamentos determinadas regiões da cidade. Isso ocasiona um desenvolvimento desigual e perpetua lógicas de exclusão e estigmatização com impactos diretos na produção de subjetividades, especialmente na criminalização de formas contra hegemônicas de apropriação do espaço.

Assim, a atividade surgiu como tentativa de problematizar essas questões que afetam diretamente também os jovens da região da Comunidade Indiana e do Complexo do Borel, bem como possibilitar momentos de reflexão e lazer ao grupo. Entendemos que a experiência que essa atividade proporcionou a seus participantes também auxiliou em um processo de desindividualização de muitos dos sofrimentos que já experimentaram por serem moradores de favelas. Sofrimentos com impactos amplos em várias dimensões de suas existências: pessoal, familiar, escolar, profissional.

Tomamos como duplo objetivo proporcionar ao grupo um espaço de troca de ideias e experiências aliadas à possibilidade de acesso àquilo que a cidade oferece, bem como fomentar a reflexão e participação desses jovens no que diz respeito às questões da comunidade, assim como da cidade como um todo, no âmbito do direito à cidade. Para tal, a metodologia consistiu em excursões semanais a diferentes lugares da cidade do Rio de Janeiro, seguidas de rodas de conversa sobre alguma temática cara à questão da cidade e que estivesse sendo visualizada nos espaços visitados. Dessa forma, circulamos por cinco diferentes pontos - o estádio de futebol Jornalista Mário Filho, internacionalmente conhecido como Maracanã; o campus Fundão da Universidade Federal do Rio de Janeiro; o museu da Maré, um dos poucos localizados dentro de uma favela e que traz as lutas histórica e diária de moradores da região; a região portuária da cidade, um local por onde desembarcaram milhares de africanos escravizados e que recentemente foi "revitalizado"; e o Aterro do Flamengo, às margens da baía de Guanabara, um dos maiores símbolos dos problemas de saneamento básico enfrentados na cidade - abordando e, em alguma medida, experimentando, temas importantes sobre cidade, como acesso ao lazer, direito à educação e à moradia, remoções, saúde, saneamento básico e mobilidade urbana.

Foi feito uso do dispositivo grupal (Barros, 2007), no qual utilizou-se outros dispositivos (como vídeos, jogos e brincadeiras), a fim de dar voz às multiplicidades e possibilitar a desindividualização das questões que surgiram no decorrer dos encontros. Também apostou-se na própria mobilização social do grupo como estratégia metodológica do trabalho, entendendo que a articulação do coletivo pode ser um instrumento promotor de autonomia, capaz de estimular uma participação política e social, portanto democrática. "Lutar por novos projetos democráticos implica buscar espaços para intervir, potencializando no cotidiano as relações diferenciadas" (Scheinvar, 2009, p. 171). Sendo assim, compreendem-se democracia e participação não enquanto produções genéricas, mas enquanto produções concretas quando discutidos os direitos em espaços de exercícios de cidadania em que a sociedade civil pode (ou deveria poder) atuar na gestão pública (Scheinvar, 2009).

A Psicologia enquanto ciência e profissão tem se questionado bastante nas últimas décadas sobre seu compromisso social, o que envolve também problematizar os espaços nos quais a(o) profissional pode e deve atuar para além das inserções clássicas na clínica, na escola, no hospital. Não existem, muitas vezes, nesse campo profissional, nem práticas, nem espaços de atuação absolutamente engessados, cabendo constantemente à(ao) psicóloga(o) construí-los, sempre visando, como orienta um dos princípios fundamentais do código de ética profissional, a promoção de saúde e qualidade de vida e a eliminação de possíveis formas de negligência, discriminação, exploração, violência e opressão.

As dificuldades encontradas por profissionais de Psicologia na busca de exercer uma práxis que seja norteada por tal compromisso, principalmente nos campos de atuação que expandiram a gama de inserções psi (comunidade, organizações sociais, políticas públicas etc.), mobilizou profissionais e programas de pesquisas universitárias a desenvolver novas teorias que superassem o viés intimista/biologicista que historicamente constituiu a Psicologia. Assim, especialmente após a década de 1970, vão surgindo trabalhos abordando temáticas relacionadas à exclusão social, consciência/alienação, identidade, contexto comunitário, afetividade, compromisso ético em Psicologia etc. Questões que precisavam ser consideradas nas análises e intervenções psicológicas na América Latina. 
Ao reforçar a importância do rompimento com a tradição elitista e da construção de uma nova concepção de homem na Psicologia, Silvia Lane, professora pesquisadora pela Pontifícia Universidade Católica de São Paulo desde os anos 1960 até os anos 2000, foi uma das pioneiras a apontar as condições para um novo projeto profissional. Bock, Ferreira, Gonçalves e Furtado (2007) afirmam que havia uma grande preocupação por parte de Silvia para que pudesse ser extirpado o hábito de fazer da realidade um exemplo dos conceitos teóricos. Em contraposição, seu "objetivo era produzir conhecimento que possibilitasse uma compreensão da realidade que implicasse, necessariamente, sua transformação" (p. 48). Em outras palavras, as construções teóricas somente fazem sentido diante de um comprometimento social, que mais do que afirmar uma unidade entre saber e fazer (não havendo, portanto, espaço para que a realidade pudesse ser tomada enquanto mero exemplo de conceitos), tem como principal propósito o engajamento na transformação daquilo que se apresenta. Afinal, os fenômenos sociais não são inatos.

Conforme vai se desenvolvendo, esse já não tão novo projeto profissional da Psicologia, a transformação adquire cada vez mais o sentido de superação da desigualdade social (produzida, e não inata, e manifestada sob as formas de renda, mas também educacionais, urbanísticas, de mobilidade urbana) e das situações de opressão que nos constituem enquanto sujeitos brasileiros, latino-americanos. E nesse intuito, a produção teórica de Silvia Lane acerca do psiquismo, como indissociado de um conteúdo histórico e social, é indispensável para situar a Psicologia enquanto um saber responsável por "compreender o indivíduo em sua relação dialética com a sociedade; a constituição histórica e social do indivíduo e os elementos que explicam os processos de consciência e alienação; e as possibilidades de ação do homem frente às determinações sociais" (Bock et al., 2007, p. 50).

Nada se pode afirmar sobre o sujeito sem considerar a realidade social da qual participa, o que impõe a nós, psicólogas(os), um lugar no processo de transformação social em qualquer área na qual nos propomos a atuar. Bock et al. (2007) lembram que, para Lane, o mais importante não era o tema da pesquisa de seus orientandos, mas a resposta para "qual a realidade que queriam contribuir para mudar" (p. 55).

Caminhando na mesma direção, Martín-Baró (1996) afirma que para assumirmos o papel que deve- mos desempenhar em nossas sociedades enquanto psicólogas(os) é importante examinar as circunstâncias concretas da população a que vamos atender, sua situação histórica e suas necessidades. Muitas das críticas feitas às(aos) profissionais de Psicologia residem no fato de que a dedicação da sua atenção é dirigida aos setores mais abastados da sociedade e a centralidade da sua atenção às raízes pessoais dos problemas, esquecendo-se ou menosprezando os fatores sociais. Com esse enfoque e essa clientela, acabam por servir aos interesses da ordem social estabelecida, convertendo-se em instrumento útil para a manutenção e reprodução do sistema, à medida que "continuam sonhando com o exercício liberal de uma profissão que atende aos privilegiados e que considera os excluídos como fontes de contaminação e violência patológica" (Osorio, 2011, p. 69).

Osorio (2011) pontua que, no contexto da filosofia neoliberal, as(os) profissionais de Psicologia encontram-se em conflito na sua prática: juraram que o fundamento principal é o interesse de quem demanda sua atenção, mas seu saber está "a serviço do capital, sob as premissas dogmáticas de que a ciência deve ser neutra, asséptica e pragmática” (p. 66). Martín-Baró (1986) ressalta que nesse cenário tem influência a colonização do saber psi latino-americano - cujo nascimento e desenvolvimento se deu a partir do lugar de imitadores e difusores da Psicologia estadunidense e europeia evidenciada a partir de três fatores: desejo de adquirir um reconhecimento científico; carência de uma epistemologia adequada, que parta dos povos latino-americanos; e preocupação com falsos problemas, especificamente no que se referem a um alijamento quanto à realidade da América Latina.

Contudo, concordamos com Osorio (2011) quando afirma que estão aí igualmente em atuação as forças que sustentam o processo de globalização centrada no mercado, o qual necessita de indivíduos para se sustentar. Sob o pretexto da "democratização" advinda com a formação de uma sociedade mundial única, "a Psicologia converte-se em instrumento que mantém vivo o paradoxo da inclusão, por meio de modelos de 'integração' que excluem” (Osorio, 2011, p. 71). O ser humano é destituído de sentido frente a necessidade do melhor interesse do mercado; a ciência é reduzida à tecnocracia. O desenvolvimento do processo globalizador acarreta numa pressão sobre os governos para que criem espaços sociais a favor das empresas transnacionais e multinacionais. Eis o real 
significado da imposição democrática na América Latina, que "visava" a redução de sua pobreza.

Em contrapartida a essa realidade de exercício profissional, Martín-Baró (1986) e outros praticantes da Psicologia da Libertação, cansados de explicações individualizantes e psicologizantes para as causas do subdesenvolvimento da América Latina, atentaram-se para as relações de dependência e de exploração aí vigentes, as quais deveriam ser suprimidas ou transformadas para que de fato se pudesse ocorrer o desenvolvimento regional. Eles assumiram a obrigação ética de trabalhar a favor dos excluídos, o que implica negar o processo globalizador, tanto em virtude das condições de desigualdade e exclusão que ele é responsável por acirrar, quanto pela necessidade que essa obrigação impõe no sentido de afirmar as tradições e práticas dos oprimidos (Osorio, 2011).

Nesse contexto, é preciso lembrar que, para praticar uma Psicologia da Libertação, faz-se importante uma libertação da própria Psicologia (Martín-Baró, 1986) e, de acordo com Martín-Baró (1996), a conscientização deve constituir o horizonte do fazer psicológico liberto e libertador. Esse processo busca a desalienação das pessoas e grupos e ajuda a chegar a um saber crítico sobre si mesmas e sobre sua realidade, através da eliminação e controle dos mecanismos que bloqueiam a consciência da identidade pessoal e social. Tal papel somente é possível porque, para Martin-Baró (1996, p. 14), "a consciência [...] é [...] sobretudo, aquele âmbito onde cada pessoa encontra o impacto refletido de seu ser e de seu fazer na sociedade, onde assume e elabora um saber sobre si mesmo e sobre a realidade que lhe permite ter uma identidade pessoal e social". Ele ressalta que não só o saber, mas também o não saber (práxico, mais que mental), sobre si, os demais e o próprio mundo, é que constituem a consciência, defendendo o processo conscientizador como aquele voltado primeiramente a devolver a palavra às pessoas, não somente como indivíduos, mas como parte de um coletivo. "O saber mais importante do ponto de vista psicológico não é o conhecimento explícito e formalizado, mas esse saber inserido na práxis cotidiana, [...] enquanto permite ou impede os grupos e povos de manter a sua própria existência" (Martin-Baró, 1996, p. 15).

Conscientização, como bem lembra Guareschi (2011), no sentido de palavração, ou seja, algo que demonstra a impossibilidade da dicotomia entre consciência e ação, o que por sua vez implica para a
Psicologia um compromisso com a práxis, "teoria que cria prática transformadora, prática que produz teoria, ambas refletidas" (Montero, 2011, p. 98).

Teoria, até mesmo em sua etimologia, é o que ajuda a ver de cima, como uma luz sobre um monte. Agora no momento em que fico apenas na teoria e não tenho uma prática, jamais poderei entender a realidade, porque não se pode ver a luz em si mesmo: o que se vê é sempre algo iluminado (Guareschi, 2011, p. 57).

E dessa forma, uma tarefa importante que cabe à(ao) psicóloga(o), ao buscar os meios para assumir nossa responsabilidade social, diz respeito ao reconhecimento objetivo dos problemas que afligem os povos latino-americanos e a definição da contribuição específica da Psicologia na resolução desses problemas. É colocar o nosso saber a serviço de uma sociedade mais justa e igualitária, em que o bem-estar de uma minoria favorecida não se faça sobre o mal-estar da maioria desfavorecida, e que o interesse de poucos não exija a desumanização dos demais (Martín-Baró, 1996).

De que forma as provocações de Silvia Lane, Martin-Baró e os outros praticantes da Psicologia da Libertação acerca do papel que cabe ao saber psi diante da realidade social brasileira e latino-americana podem nos auxiliar a problematizar o cenário das cidades desses países? A partir de que intervenções a prática das(os) psicólogas(os) latino-americanas(os) pode contribuir na superação das profundas desigualdades sociais que marcam a experiência humana nos centros urbanos dessa região do mundo? Tomando as reflexões de Montero (2011) acerca dos questionamentos que fazem uma prática psicológica crítica, constitui interesse de análise/intervenção, diante da realidade das cidades, ponderar alternativas, causas e efeitos; reconhecer a diversidade de atores sociais envolvidos, sua pluralidade de formas de ação, assim como sua capacidade de produzir transformações; além de relacionar o fenômeno da "cidade enquanto campo em disputa" com seu contexto cultural, histórico e social.

A maneira como o espaço urbano de uma cidade se estrutura e se modifica está intimamente relacionada com a forma como se dão as interações sociais da população que nele vive. Tais interações, por sua vez, refletem a maneira como, ao longo do tempo, diferentes segmentos sociais se apropriam desse território. Apropriação cujos modos derivam de questões 
relacionadas à historicidade com o local, ao pertencimento, aos vínculos entre indivíduos e grupos, às manifestações culturais, aos processos de desenvolvimento econômico, às políticas de planejamento urbano e outros (Lefebvre, 2001). Ou seja, de acordo com Lefebvre, o espaço se configura como um dos elementos instigantes das interações da sociedade, observando que, nas cidades, as misturas culturais e sociais se fazem obrigatórias, possibilitando diferentes formas de subjetivação.

No Rio de Janeiro e em outras metrópoles latino-americanas, o planejamento urbano e o direito à cidade vêm sofrendo contundentes interferências do modelo neoliberal, colocando em conflito os interesses de quem habita o território e os de grandes corporações do capital financeiro (Faulhaber, \& Azevedo, 2015). E tais interferências agravam problemas já conhecidos. O direito à moradia, saneamento básico, mobilidade urbana, o acesso a equipamentos culturais, esportivos e de lazer ainda são negados a boa parte de moradoras e moradores da cidade. Isso por vezes acarreta uma multiplicidade de formas contra hegemônicas de apropriação/construção do espaço urbano, algumas delas criminalizadas (e, portanto, passíveis de diferentes tipos de sanções) por serem desviantes de uma ordem instituída como padrão. E aí tem forte influência certo uso de uma garantia de segurança na gestão da cidade-negócio (Barbosa, 2017).

Por trás dessas transformações, surgem novos significados e possibilidades de relações que alteram dinâmicas da cidade, que se inscreve em muros simbólicos e reais, em trajetos, acessos, fronteiras e olhares. Como aponta Santos (1987), percebemos que, na cidade, "cada homem vale pelo lugar onde está" (p. 81), demonstrando que a luta pela apropriação do espaço é também uma disputa pelo estabelecimento de poder. O tecido urbano é história que se produz continuamente, revelando contradições produzidas pelo desenvolvimento desigual das relações sociais. Quem sofre com o processo de desqualificação social vê sua condição de sujeito esvaziada, enquanto que aqueles, em posições favoráveis, se valem disso para reforçar seus lugares sociais, valorizando sua identidade de pertencimento em contraponto àquela desqualificada.

Nesse cenário, faz-se necessária uma Psicologia comprometida em intervir na realidade que vem sendo imposta a partir de uma perspectiva de cida- de-negócio por meio de práticas que afirmam uma visão de cidade que não privilegie este espaço para especulação e obtenção de lucro. Uma Psicologia que tenha a luta e participação política como metas para uma experiência democrática de sociedade, consolidando dessa forma o compromisso social como norteador da profissão. Uma Psicologia comprometida com a democratização do país a partir da democratização de suas cidades; que luta por direitos e contra a exploração e as opressões que se atualizam a partir da imposição de um modelo de cidade-negócio; e que contribua nos enfrentamentos emancipatórios pela democracia no Brasil e na América Latina, especialmente considerando os efeitos da disputa pela cidade.

Contudo, concordamos que a discussão sobre modelos de cidade (e seus efeitos sobre as pessoas) que se encontram em vigência ou pelos quais se lutam para que possam ser modificados pode, a princípio, parecer muito distante a área de abrangência do saber psi. Todavia, esmiuçar as forças em operação que constituem as lógicas imperativas nas cidades, e entre elas na cidade-negócio, constitui-se campo fértil para compreensão das produções de subjetividade em andamento.

A constatação de que a relação entre subjetividade e objetividade não se trata de uma polarização, mas sim de uma dialética, foi uma contribuição importante que Lane (2004), embasada nos pressupostos marxistas do materialismo histórico dialético, forneceu como ferramenta de análise psi. Através dela é possível afirmar que toda ação humana, inclusive aquelas que dizem respeito a elaboração e implementação de políticas para a cidade, não está isenta daquilo que nos constitui enquanto sujeitos situados num contexto que necessariamente é atravessado por uma história e materialidade.

Não há, portanto, a possibilidade de se sustentar qualquer ideia ou ação que se pretende neutra, conceito tão comumente associado à objetividade e defendido pelo positivismo. A aprovação de leis e políticas que visam estabelecer marcos regulatórios relacionadas à habitação (como um plano diretor), apesar de aparente objetividade, estão permeadas pelos processos de subjetivação que atravessam determinado grupo, o que se constitui necessariamente como campo para Psicologia. Subjetivamos, ao objetivar e vice-versa, uma espiral constituída no decorrer do tempo, refutando dicotomias para dar lugar à dialética sujeito-sociedade! 
Quando o poder público se coloca no papel de limitar a circulação da população pobre nos espaços abastados da cidade, a partir de extinção de linhas de ônibus, alta nos preços de passagens ou mesmo pelas violações perpetradas pelos agentes de segurança pública, isso produz também subjetividade em todo o tecido social. O estigma evidenciado pelos policiais que impedem a circulação de jovens negros para as praias da zona sul do Rio de Janeiro (Heringer, \& Barros, 2015) marca de forma potente esses sujeitos pela desvalorização que sentem pelo Estado, principalmente quando se encontram em determinados territórios. As políticas de cidade, portanto, geram afetos, fazendo emergir a necessidade de conhecimentos e intervenções que possam considerar a dimensão da afetividade para a preservação de direitos.

As relações aqui problematizadas entre cidade e subjetividade podem ser evidenciadas na disputa que ocorre hoje no Rio de Janeiro e, no espaço geográfico, apresentam-se as marcas dessa disputa. Baptista (2001) ilustra e analisa, com o caso das Mães da Praça de $\mathrm{Maio}^{6}$, fenômeno semelhante. Conta o autor que "as mulheres argentinas, renunciando a missão do conformismo a elas delegado pelo torpor do sofrimento, fazem da praça o lugar atravessado por desejos e revoltas promotoras de criação" (p. 195). Tal como as Mães da Praça de Maio, moradores da Indiana canalizaram medo e sofrimento para resistir à possibilidade de remoção desejada pela Secretaria Municipal de Habitação da prefeitura. Outros exemplos se fazem notar, como nos emblemáticos casos de disputas na Comunidade da Vila Autódromo, Aldeia Maracanã, dentre outros, onde nem mesmo a racionalidade neoliberal, travestida com um discurso supostamente desenvolvimentista para a cidade, foi capaz de silenciar os moradores atingidos.

A afetividade foi outra categoria de análise desenvolvida por essa Psicologia Social Crítica a que temos nos referido. Sawaia (2009), a partir das contribuições de Espinosa, esclarece o papel que os afetos têm em aumentar nossa potência de agir. A autora desenvolve importantes pressupostos sobre a dialética inclusão-exclusão através dessa categoria. Para ela:

Perguntar por sofrimento e por felicidade no estudo da exclusão é superar a concepção de que a preocupação do pobre é unicamente a sobrevivência e que não tem justificativa trabalhar a emoção quando se passa fome. Epistemologicamente, significa colocar no centro das reflexões sobre exclusão, a idéia de humanidade e como temática o sujeito e a maneira como se relaciona com o social (família, trabalho, lazer e sociedade), de forma que, ao falar de exclusão, fala-se de desejo, temporalidade e de afetividade, ao mesmo tempo que de poder, de economia e de direitos sociais (Sawaia, 2001, p. 98).

Supera-se o imaginário de que a afetividade apenas deturpava o rigor científico para compreendê-la dentro da complexidade que constitui os fenômenos sociais. Busca-se, assim, entender a produção subjetiva-objetiva mediada pelas emoções na dinâmica sujeito-sociedade.

Vilhena (2002) vai ao encontro dessa mesma discussão ao ressaltar a dimensão simbólica do lugar na dimensão psíquica, lembrando que os sujeitos frequentemente remetem-se aos lugares que os marcaram ao longo de suas vidas. Ela destaca que "é a partir dele que é possível pensar o viver, trabalhar, formar laços sociais e identificar-se com os semelhantes. Pois é a partir de um lugar [...] que falamos e somos ouvidos, respeitamos e somos respeitados, sentimo-nos incluídos ou à margem" (p. 50). Dessa maneira, a autora nos convida a pensar sobre os efeitos provocados pela desconfiança e temor ao outro, que marcam a convivência entre diferentes segmentos sociais em nossa cidade. Ela alerta para o sofrimento experimentado por certos segmentos que não fazem parte daqueles modelos identificatórios ideais e considera que "a imagem construída pelo seu meio social, nas relações com seus próximos, com a cultura na qual o sujeito se insere, é fator privilegiado da constituição do sujeito" (p. 52).

Autores como Silva e Barbosa (2005, p. 100) afirmam outra dimensão dessa relação entre subjetividade e territorialidade ao definirem a cidade como "obra humana territorialmente impressa". Para eles, falar em sociedade é o mesmo que tratar de uma relação sujeito-território, afinal, as categorias de compreensão do modo de vida humano são, necessariamente, atravessadas pela dimensão espacial. Lefebvre (2001)

${ }^{6}$ No dia 30 de abril de 2017 completou-se 40 anos do movimento das Mães da Praça de Maio, coletivo que se iniciou em resposta à ditadura militar argentina frente aos inúmeros casos de desaparecimento de crianças filhas de mães ativistas (Andrade, 2017). 
traz outros elementos para essa perspectiva de explicação para a cidade, ressaltando que ela está entre as relações dos indivíduos em grupos e a ordem determinada por grandes e poderosas instituições, por um código jurídico, formalizado ou não.

No entanto, mais do que demonstrar, a partir de suas concepções, uma relação entre diferentes constituições de ser e estar no mundo (ou seja, subjetivação) e a experiência urbana, os autores citados apontam para o modelo de cidade por cujo direito se reclama: aquele em que está garantido o direito à produção do espaço (Harvey, 2014), que também é produção de si. E nessas discussões é fundamental que outro aspecto da experiência humana em sociedade possa ser considerado: a democracia. Pautar a lógica que rege as cidades, sua organização e gestão, é também colocar em evidência o exercício ou não de instrumentos democráticos. E, nesse sentido, "pensar o Rio hoje é central não só por sua importância histórica, mas porque ele é o laboratório de um modelo de cidade voltada para o capital, a cidade-negócio, em que a gestão pública é controlada por empresas sócias da prefeitura". Isso significa que, na sustentação desse modelo de cidade, o Estado exerce papel fundamental, na medida em que permite a gestão das políticas públicas pela iniciativa privada, afastando assim ao máximo a participação da população nas decisões de interesse público e consequentemente a soberania popular e a "dimensão pública da cidade enquanto espaço de fazer político”.

\section{Últimas considerações}

O espaço urbano atua em processos de produção de subjetividades e enquanto psicólogas(os), ao nos debruçarmos sobre o ser humano, objeto de nosso estudo, devemos levar em consideração a construção do espaço urbano - a qual ocorre segundo mecanismos mais, menos ou quase nada democráticos - e as implicações desse contexto nos processos de subjetivação. A categoria espaço é elemento imprescindível para a realização de uma análise da vida social, reforçando o nosso compromisso político de não desconhecer a complexidade do humano, tomando, para tanto, a produção da subjetividade em relação à produção do espaço urbano. Só se pode compreender a relação cidade/subjetividade a partir de um movimento dialético. Para a compreensão da experiência de vida de seus habitantes, é necessário pensar sobre a cidade, assim como para pensar a subjetividade é preciso pensar o espaço.

Sendo assim, temos um imenso compromisso a assumir. Enquanto área de saber, a Psicologia deve contribuir nas discussões sobre cidade. Em especial diante desse cenário de cidade que se apresenta: cidade enquanto campo em disputa, no qual ocorrem graves ameaças a um desenvolvimento democrático da gestão de bens e existências coletivas. Mas sobre que fundamentos devem ser construídas as contribuições dessa área do saber? Acredita-se naqueles defendidos por Martín-Baró (1996), e outros praticantes da Psicologia da Libertação, que aposta no processo conscientizador, tendo em vista que a modificação da realidade impõe modificações ao ser humano; que a decodificação do mundo permite o conhecimento sobre mecanismos de opressão e desumanização; e que um novo saber sobre a realidade leva a um novo saber sobre si e sobre seu coletivo.

Dessa forma, conclui-se que se está diante de mais do que um campo para atuação da Psicologia. Trata-se de um compromisso, que é social, ético e político, o qual, portanto, não pode ser assumido de maneira neutra. Como critica Martín-Baró (1996), não se convoca a Psicologia para intervir em mecanismos socioeconômicos, mas sim a atuar frente aos processos subjetivos que sustentam e viabilizam estruturas injustas que decorrem desses mecanismos. É preciso romper com esse lugar. O casamento entre Psicologia e democracia somente ocorre quando o saber psi contribui com a formação de uma identidade pessoal e coletiva advinda das necessidades reais dos grupos subalternizados. A intervenção aqui descrita, cujos objetivos contemplam a luta e a participação política e que é disparadora dessas reflexões sobre Psicologia e democracia, abarca implicações ético-políticas de um fazer num momento histórico-social em que a luta pela democratização do país abrange uma interferência na disputa pela cidade.

\section{Referências}

Andrade, J. (Ed.). (2017, 30 de abril). Mães da Praça de Maio completam 40 anos de luta pela memória e pela vida. Agência Brasil. Recuperado de http://agenciabrasil.ebc.com.br/internacional/noticia/2017-04/maes-da-praca-de-maio-completam-40-anos-de-luta-pela-memoria-e-pela 
Ávila, P. C., \& Ferreira, F. P. M. (2016). A insegurança da posse do solo urbano em Minas Gerais. Urbe: Revista Brasileira de Gestão Urbana, 8(2), 197-210. https://doi.org/10.1590/2175-3369.008.002.ao03

Baptista, L. A. S. (2001). Cidades, lugares e subjetividade: contribuições da política e da literatura. In M. Ciavatta, \& G. Frigotto (Org.), Teoria e educação no labirinto do capital (pp. 194-203). Rio de Janeiro, RJ: Vozes.

Barbosa, R. B. (2017). Políticas sobre drogas, direito à cidade e processos de subjetivação: "porque dignidade não pode ter endereço". Tese de doutorado, Universidade Federal do Rio de Janeiro.

Barros, R. B. (2007). Grupo. A afirmação de um simulacro. Porto Alegre, RS: Sulina.

Bastos, I., \& Schmidt, S. (2011). Prefeitura removerá 119 favelas até o fim de 2012. O Globo. Recuperado de https:// oglobo.globo.com/rio/prefeitura-removera-119-favelas-ate-fim-de-2012-3072053

Bock, A. M. B., Ferreira, M. R., Gonçalves, M. G. M., \& Furtado, O. (2007). Sílvia Lane e o projeto do "Compromisso Social da Psicologia”. Revista Psicologia \& Sociedade, 19(2), 46-56. https://doi.org/10.1590/S010271822007000500018

Brasil. Secretaria de Direitos Humanos. (2013). Direito à moradia adequada. Brasília, DF: o autor.

Brasil. Senado Federal (1988). Constituição da República Federativa do Brasil. Brasília, DF: o autor.

Carlos, A.F.A., Volochko, D. \& Alvarez, I. P. (2015). A cidade como negócio. São Paulo, SP: Contexto.

Clarke, F. (2014, 27 de fevereiro). Incerteza, divisão e resistência: remoção na Indiana. Rioonwatch. Recuperado de http://rioonwatch.org.br/?p=10238

Comitê Popular da Copa e Olimpíadas do Rio de Janeiro. (2015). Megaeventos e violações dos direitos humanos no Rio de Janeiro. Disponível em https://br.boell.org/sites/default/files/dossiecomiterio2015___portugues.pdf

Conselho Federal de Psicologia. (2005). Resolução CFP no 010/2005. Aprova o Código de Ética Profissional do Psicólogo. Recuperado de http://site.cfp.org.br/wp-content/uploads/2012/07/codigo_etica.pdf

Faulhaber, L., \& Azevedo, L. (2015). SMH: 2016 Remoções no Rio de Janeiro olímpico. Rio de Janeiro, RJ: Mórula.

Fichino, D., Marinho, G., \& Campagnani, M. (2016). Guia para jornalistas e comunicadores: violações de direitos na Cidade Olímpica. Recuperado de http://www.global.org.br/wp-content/uploads/2016/07/guia_jornalistas_violacoes_olimpiadas.pdf

Freixo, M. Título. (2016). Recuperado de http://www.marcelofreixo.com.br/2016/03/15/freixo-na-ucam-futuro-da-democracia-passa-pelas-cidades /

Grotti, D. A. M (2000). Conceitos jurídicos indeterminados e discricionariedade administrativa. Atualidades Jurídicas, 2: 103-141.

Guareschi, P. (2011). Pressupostos epistemológicos implícitos no conceito de libertação. In R. S. L. Guzzo, \& F. Lacerda Junior (Org.), Psicologia social para América Latina: o resgate da psicologia da libertação (2a ed., pp. 49-63). Campinas, SP: Alínea.

Harvey, D. (2014). Cidades rebeldes: do direito à cidade à revolução urbana (Jeferson Camargo, trad.). São Paulo: Martins Fontes.

Heringer, C., \& Barros R. (2015, 7 de setembro). PM aborda ônibus e recolhe adolescentes a caminho das praias da Zona Sul do Rio. Extra. Recuperado de https://extra.globo.com/noticias/rio/pm-aborda-onibus-recolhe-adolescentes-caminho-das-praias-da-zona-sul-do-rio-17279753.html

Lane, S. T. M. (2004). A psicologia social e uma nova concepção de homem para a psicologia. In S. T. M. Lane, \&W. Codo (Org.), Psicologia social: o homem em movimento (pp. 10-19). São Paulo, SP: Brasiliense.

Lefebvre, H. (2001). O direito à cidade (Rubens Eduardo Frias, trad.). São Paulo, SP: Centauro.

Magalhães, A. F. (2013). O direito das favelas. Rio de Janeiro, RJ: Letra Capital

Maricato, E. (2009). Globalização e política urbana na periferia do capitalismo. Revista VeraCidade, 4(4). Recuperado de http://www.veracidade.salvador.ba.gov.br/v4/images/pdf/artigo7.pdf

Martín-Baró, I. (1996). O papel do Psicólogo. Estudos de Psicologia (Natal), 2(1): 7-27. https://doi.org/10.1590/ S1413-294X1997000100002 
Montero, M. (2011). Ser, fazer e parecer crítica e libertação na América Latina. In R. S. L. Guzzo, \& F. Lacerda Junior (Org.), Psicologia social para América Latina: o resgate da psicologia da libertação (2a ed., pp. 65-84). Campinas, SP: Alínea.

Nações Unidas no Brasil - ONUBR. (2013, 18 de fevereiro). Direito à moradia adequada: relatora da ONU apresenta primeiro estudo de segurança da posse. Brasília, DF: o autor. Recuperado de https://nacoesunidas.org/direito-a-moradia-adequada-relatora-da-onu-apresenta-primeiro-estudo-de-seguranca-da-posse/

Osorio J. M. F. (2011). Ética e Construção social da libertação latino-americana. In R. S. L. Guzzo, \& F. Lacerda Junior (Org.), Psicologia social para América Latina: o resgate da psicologia da libertação (2a ed., pp. 87-100). Campinas, SP: Alínea.

Robertson, D. (2016, 20 de maio). Ocupação Vito Giannotti na região portuária enfrenta pressão jurídica e incerteza. Rioonwatch. Recuperado de http://rioonwatch.org.br/?p=19868

Rolnik, R. (2015). Guerra dos lugares: a colonização da terra e da moradia na terra das finanças. São Paulo, SP: Boitempo

Santos, M (1987). O espaço do cidadão. São Paulo, SP: Nobel, 1987.

Santos, M. (1999). A natureza do espaço: técnica e tempo, razão e emoção. São Paulo, SP: Hucitec.

Santos, M. (2006). A natureza do espaço: técnica e tempo, razão e emoção (4a ed.) São Paulo, SP: Editora da Universidade de São Paulo.

Sawaia, B. B. (2001). O sofrimento ético-político como categoria de análise para a dialética exclusão/inclusão. In B. B. Sawaia (Org.). As artimanhas da exclusão: análise psicossocial e ética da desigualdade social. Petrópolis, RJ: Vozes.

Sawaia, B. B. (2009). Psicologia e desigualdade social: uma reflexão sobre liberdade e transformação social. Psicologia \& Sociedade, 21(3), 364-372. https://doi.org/10.1590/S0102-71822009000300010

Scheinvar, E. (2009). O feitiço da política pública: escola, sociedade civil e direitos da criança e do adolescente. Rio de Janeiro, SP: Lamparina.

Silva, J. S., \& Barbosa, J. L. (2005). Favela: alegria e dor na cidade. Rio de Janeiro, RJ: Editora Senac Rio.

Talbot, A. (2016, 26 de maio). Apagando a Favela da Vila Autódromo. Riononwatch. Recuperado de http:// rioonwatch.org.br/?p=19959

Vilhena, J. (2002). Da cidade onde vivemos a uma clínica do território: lugar e produção de subjetividade Pulsional Revista de Psicanálise, 15(163): 48-54.

Williamson, T. (2012, 8 de maio). A remoção lenta e sofrida da favela Metrô-Mangueira. Rioonwatch. Recuperado de http://rioonwatch.org.br/?p=3051

\section{Elisa Martins}

Graduanda em Psicologia pela Universidade Federal do Rio de Janeiro - UFRJ. Extensionista no Núcleo Interdisciplinar de Ações para a Cidadania (NIAC-UFRJ). Bolsista Profaex.

E-mail: martinsselisa@gmail.com

\section{Fhillipe Pereira}

Graduando em Psicologia pela Universidade Federal do Rio de Janeiro - UFRJ. Extensionista no Núcleo Interdisciplinar de Ações para a Cidadania (NIAC-UFRJ). Bolsista Profaex.

E-mail: fhillipepsico@gmail.com

\section{Gabriela Salem}

Psicóloga pela Universidade Federal do Rio de Janeiro - UFRJ. Voluntária no Núcleo Interdisciplinar de Ações para a Cidadania (NIAC-UFRJ).

E-mail: salemgabriela@gmail.com 


\section{Lucas Gabriel de Matos Santos}

Graduando em Psicologia pela Universidade Federal do Rio de Janeiro. Bolsista de iniciação científica no Núcleo Interdisciplinar de Ações para a Cidadania (NIAC-UFRJ). Bolsista CNPq.

E-mail: lucasgabrieldematos@gmail.com

\section{Roberta Brasilino Barbosa}

Psicóloga e Pós-doutoranda em Psicologia pelo Programa de Pós-Graduação em Psicologia da Universidade Federal do Rio de Janeiro - UFRJ. Supervisora da equipe de Psicologia do Núcleo Interdisciplinar de Ações para Cidadania (NIAC-UFRJ). Membro da Comissão Nacional de Direitos Humanos do Conselho Federal de Psicologia. E-mail: robertabrasilino@gmail.com

Endereço para envio de correspondência:

Av. Pasteur 250 - Pavilhão Nilton Campos, 2º andar, Urca, Rio de Janeiro/RJ. CEP nº 22290-902

Recebido 30/06/2017

Reformulação 07/09/2017

Aprovado 13/09/2017

Received 06/30/2017

Reformulated 09/07/2017

Approved 09/13/2017

Recebido 30/06/2017

Reformulado 07/09/2017

Aceptado 13/09/2017

Como citar: Martins, E., Pereira, F., Salem, G., Santos, L. G. M., Barbosa, R. B.(2017). Psicologia e Democracia em um Cenário de Cidade como Campo em Disputa. Psicologia: Ciência e Profissão, 37(n. spe), $224-238$. https://doi.org/10.1590/1982-3703170002017

How to cite: Martins, E., Pereira, F., Salem, G., Santos, L. G. M., Barbosa, R. B (2017). Psychology and Democracy in a Scenario of the City as a Disputed Field. Psicologia: Ciência e Profissão, 37(n. spe), $224-238$. https://doi.org/10.1590/1982-3703170002017

Cómo citar: Martins, E., Pereira, F., Salem, G., Santos, L. G. M., Barbosa, R. B (2017). Psicología y Democracia en un Escenario de Ciudad como Campo en Disputa. Psicologia: Ciência e Profissão, 37(n. spe), $224-238$. https://doi.org/10.1590/1982-3703170002017 